\title{
USE OF THE TENSORFLOW FRAMEWORK TO SUPPORT EDUCATIONAL PROBLEMS: A SYSTEMATIC MAPPING
}

\author{
Padilha $\mathrm{TPP}^{1^{*}}$ and Catrambone $\mathrm{R}^{2}$ \\ ${ }^{1}$ Federal University of Paraíba, Brazil \\ ${ }^{2}$ Georgia Institute of Technology, USA
}

\begin{abstract}
The Google framework called TensorFlow has been widely used for decision making in several areas, including Education. Predicting student risk and optimizing a student's learning path are, for example, two traditional educational problems that have been explored for years but there are a myriad of different data mining approaches involved. This paper's goal is to illustrate the results of a systematic mapping process conducted on educational data mining studies using the TensorFlow framework. Furthermore, this paper will assist in illustrating what kind of problems to focus on (which can paradoxically be seen as opportunities), identify, demonstrate, and catalogue all the academic studies that have discussed it, and the approaches leveraged (neural network, decision tree, natural language processing, and so on). The mapping process followed five phases with rigor, returning a set of 32 relevant papers in the study area with detailed information related to the research questions. The outcome of this systematic study will be of benefit to academic managers, researchers, and students who use this framework as support to solve educational problems.
\end{abstract}

Keywords: systematic mapping; Educational problems; TensorFlow; data mining

\section{Introduction}

There is a plethora of academic and personal data stored in educational institutions. Data retention timeframes vary by institution; as an example, scholarly research is retained between 5 and 10 years. Students' data can include birthdate, parents' income, grades, classes taken, dissertation defense date, and so on. Teachers' data includes classes taught per semester, research projects, supervisions, etc. Therefore, there are several kinds of data that can be filtered, analyzed, and extracted to identify useful information for the decision making process, such as identifying students' learning progress during an academic degree. Different machine learning approaches have been applied in these databases for several years, but the Google framework (called TensorFlow) has gained increasing attention because it allows the process to be faster and easier, thus revolutionizing this field.

TensorFlow (https://www.tensorflow.org/) was created in 2015 by the Google Brain team to design, build, and train deep learning models - a complex algorithm that could be applied in a simplistic fashion. The 2.0 version of TensorFlow was announced in January of 2019 and launched September 2019 (Abadi et al., 2016). Many well-known companies such as Coca-Cola, GE Healthcare, and Airbnb use TensorFlow as a solution for various problems. However, anyone that utilizes Google products (e.g., Gmail, Photo, Search) already enjoys its technology implicitly such as when words are predicted when one types a message or when recommendations are made about videos to watch. 
TensorFlow works on the concept of the data flow graph for numerical computation, in which each node represents the operations, and its edges are called tensors (multidimensional array). Tensor is an object that has three properties: name (label), shape (dimensionality of the array), and type (data type). TensorFlow has gained popularity over the years because the computation of these data flow graphs runs within a session on one or more CPUs or GPUs in a desktop, server or mobile device. A typical TensorFlow application has two distinct phases: the first defines the program (e.g., a neural network to be trained) as a symbolic dataflow graph with placeholders for the input data; and the second executes an optimized version of the program on the set of available devices (Abadi et al., 2016).

In the literature, it is possible to find some systematic reviews/mappings regarding Educational Data Mining (EDM), such as Bakhshinategh et al. (2017), Hernández-Blanco et al. (2019), Holmes(2020); however, they do not mention use of TensorFlow framework in the context. Thus, this paper highlights the challenges that researchers of the Computer Science teaching degree have about this study area. In the present work, the goal was to search the literature for studies that applied the TensorFlow framework to support educational problem such as student modeling, knowledge tracing, evaluation, and so on. Therefore, it is important to know where and when the research has been published, what type of specific topic (category) was examined, the learning approaches that were used, and the key goal.

The present paper is organized as follows. Section 2 details the 5 phases of the methodology used for systematic mapping. Section 3 provides the elaborated research questions, defines inclusion and exclusion criteria, identifies the search string used and the digital libraries that were examined. Section 3 also shows the final set of selected papers (32) and highlights their categories, approaches, and publication venues. Finally, Section 4 presents the conclusion.

\section{Methods}

This section describes the methodology followed to realize this systematic mapping. In this work, we used the systematic mapping process proposed by Petersen et al. (2008) and has five main phases, as shown in the Figure 1. Each of these phases has an output.

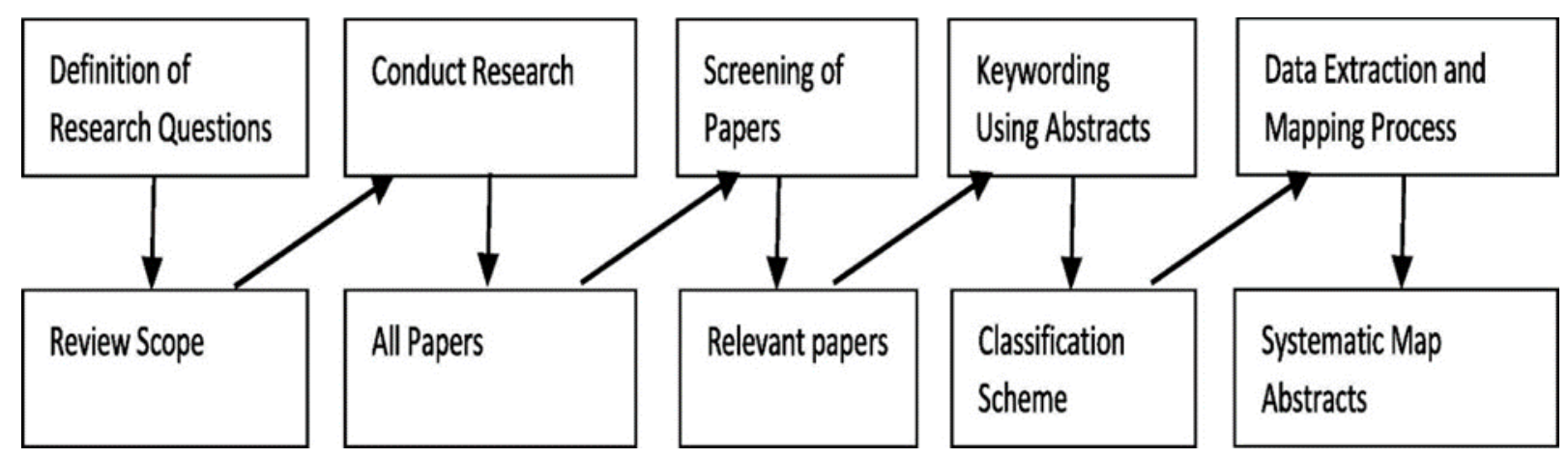

Figure 1. The Mapping Process (Petersen et al., 2008).

The Definition of Research Questions is the first phase of a mapping process that it is directed to develop one or more research questions according to the goal and the scope of the review. The Conduct Research phase consists of retrieving all papers applicable in the area of study from virtual libraries using keywords or specific terms. The Screening of Papers phase consists of reviewers 
analyzing each paper collected and defining the relevant papers that will be included in the mapping process using inclusion and exclusion criteria. The Keywording Using Abstracts phase serves to create/use one classification scheme and then categorize each paper. The last phase, Data Extraction and Mapping Process, filters and focuses relevant information about the selected papers.

\section{Results \& discussion}

According to chosen systematic mapping process, the results found in this work will be shown in this section.

\section{Definition of Research Questions}

The research questions (RQ) for this study are as follows:

RQ1: What is the overall quantity of papers on this topic and from where did they originate?

RQ2: What kind of educational problems have been solved with TensorFlow framework?

RQ3: What are the existing approaches to solve these educational problems?

\section{Conduct Research}

The chosen digital libraries for this systematic mapping were ACM Digital Library (https://dl.acm.org/), Spring Link (https://link.springer.com/), Science Direct (https://www.sciencedirect.com/) and ProQuest (http://www. https://about.proquest.com/) because they are relevant and contain general computer science archives.

The searches were performed in July 2020. According to previously defined questions, the search string used in this work was:

("Tensorflow") AND ("educational data" OR "student data" OR "academic data")

A total of 52 references were collected from these four databases (12 from ACM, 25 from Spring Link, 4 from Science Direct, and 11 from ProQuest). All references were saved to Zotero software, a free and easy-to-use reference management tool that is very useful for collecting, organizing, reading, citing, and sharing research.

\section{Screening of Papers}

The importance of the selection criteria in this study lies in its ability to review only relevant papers. Therefore, the inclusion (IC) and exclusion (EC) criteria, as shown in Table 1, were utilized in this study for deciding on pertinent papers about Data Mining using TensorFlow in the Educational area. 
Table 1. Inclusion and exclusion criteria used to screen papers

\begin{tabular}{|l|l|}
\hline Inclusion Criteria & Exclusion Criteria \\
\hline $\begin{array}{l}\text { IC1 - Studies that mention any data mining approach } \\
\text { for educational problems in the } \\
\text { title/abstract/introduction }\end{array}$ & EC1 - Duplicated studies (keep the newest) \\
\hline $\begin{array}{l}\text { IC2 - Studies that contain TensorFlow in the } \\
\text { abstract/introduction or as keyword }\end{array}$ & EC2 - Studies in book format \\
\hline
\end{tabular}

Initially, each paper was evaluated based on its title. If it was not clear how to identify the proposal, the reviewer read abstract and/or the introduction to approve or reject this paper so the next criterion could be applied. In Table 2 it is possible to follow for each digital library the number of papers included and eliminated after applying the defining criteria.

Table 2. Number of Papers after Inclusion and Exclusion Criteria

\begin{tabular}{|l|l|l|l|l|l|l|}
\hline Database & Initial & IC1 & IC2 & EC1 & EC2 & Final \\
\hline ACM & 12 & 8 & 0 & 0 & 1 & 7 \\
\hline ProQuest & 11 & 9 & 0 & 0 & 0 & 9 \\
\hline Science Direct & 4 & 2 & 0 & 0 & 0 & 2 \\
\hline Spring Link & 25 & 18 & 0 & 4 & 0 & 14 \\
\hline Total & 52 & 37 & 0 & 4 & 1 & 32 \\
\hline
\end{tabular}

The final set of papers selected for deeper analysis was 32. Observing the number of publications per year, we found 1 was published in 2016, 2 in 2017, 6 in 2018, 11 in 2019, and 12 in 2020. We observed a growth of papers and a scholarly interest in this topic over the years.

\section{Keywording Using Abstracts}

As the classification of the objectives in EDM proposed by Bakhshinategh et al. (2017) has been well accepted, it was utilized to category the selected papers for this systematic mapping. After a brief reading in the 32 abstracts, we classified them in six main categories as shown in Table 3.

Table 3. Papers classified in categories

\begin{tabular}{|l|l|}
\hline Category & References \\
\hline $\begin{array}{l}\text { Student } \\
\text { Modeling }\end{array}$ & $\begin{array}{l}\text { (Olivé et al., 2018), (Teruel \& Alonso Alemany, 2018) } \\
\text { (Castro-Wunsch et al., 2017), (Malekian et al., 2020), (Vijayalakshmi \& Venkatachalapathy, } \\
\text { 2019), (Wang et al., 2019), (Boncea et al., 2019), (Pablo, 2020), (Cheng \& Zhang, 2020), } \\
\text { (Aveleyra et al., 2018), (Tsiakmaki \& Kostopoulos, 2020), (Czibula et al., 2019), (Crivei et } \\
\text { al., 2019), (Monllaó Olivé, et al., 2020), (Chunqiao et al., 2018), (Preuveneers et al., 2020), } \\
\text { (Körösi \& Farkas, 2020), (Injadat et al., 2020), (Qiu et al., 2019) }\end{array}$ \\
\hline $\begin{array}{l}\text { Representation } \\
\text { Learning }\end{array}$ & (Zhang et al., 2019) \\
\hline Knowledge & (Lee \& Yeung, 2019), (Yang \& Cheung, 2018), (Sha \& Hong, 2017) \\
\hline
\end{tabular}




\begin{tabular}{|l|l|}
\hline Tracing & \\
\hline $\begin{array}{l}\text { Pedagogical } \\
\text { Data Analytics }\end{array}$ & (Guo \& Zeng, 2020), (Hernández-Blanco, 2019), (Gudivada, et al., 2016) \\
\hline $\begin{array}{l}\text { Decision Support } \\
\text { System }\end{array}$ & $\begin{array}{l}\text { (Gutu-Robu et al., 2018), (Stoica, et al., 2019), (Holmes, 2020), } \\
\text { (Moore et al., 2019), (Pensel \& Kramer, 2020) }\end{array}$ \\
\hline Evaluation & (Doleck et al., 2020) \\
\hline
\end{tabular}

As expected, most of the papers (20) published belong to the Student Modeling category. Basically, the general focus represents cognitive aspects of student activities, such as analyzing students' performance, isolating underlying misconceptions, representing students' goals and plans, identifying prior and acquired knowledge, maintaining an episodic memory, and describing personality characteristics (Bakhshinategh et al., 2017).

\section{Data Extraction and Mapping Process}

Table 4 summarizes the number of papers published in each publication venue. There are a variety of conferences that publish papers related to this topic.

Table 4. Publication venue of the papers

\begin{tabular}{|c|c|c|}
\hline Type & Publication Venue & Number \\
\hline \multirow{2}{*}{$\begin{array}{l}\text { Book } \\
\text { Section }\end{array}$} & Encyclopedia of Education and Information Technologies & 1 \\
\hline & Handbook of Statistics & 1 \\
\hline \multirow{15}{*}{$\begin{array}{l}\text { Conference } \\
\text { Paper }\end{array}$} & Advanced Hybrid Information Processing & 1 \\
\hline & ACM SIGCSE Technical Symposium on Computer Science Education & 1 \\
\hline & ACM SIGKDD International Conference on Knowledge Discovery \& Data Mining & 1 \\
\hline & Advances in Computing and Data Sciences & 1 \\
\hline & Artificial Intelligence in Education & 1 \\
\hline & Brain Function Assessment in Learning & 1 \\
\hline & Conference on Frontiers of Educational Technologies & 1 \\
\hline & Conference on User Modeling, Adaptation and Personalization & 1 \\
\hline & European Conference on e-Learning & 1 \\
\hline & Hybrid Artificial Intelligent Systems & 1 \\
\hline & International Conference on Data Science, E-learning and Information Systems & 1 \\
\hline & International Conference on Learning Analytics \& Knowledge & 2 \\
\hline & Knowledge Science, Engineering and Management & 1 \\
\hline & Machine Learning and Knowledge Discovery in Databases & 1 \\
\hline & The International Scientific Conference eLearning and Software for Education & 1 \\
\hline \multirow{8}{*}{$\begin{array}{l}\text { Journal } \\
\text { Article }\end{array}$} & Applied Intelligence & 1 \\
\hline & Applied Sciences & 1 \\
\hline & Cognitive Computation & 1 \\
\hline & Complexity & 1 \\
\hline & Computing & 2 \\
\hline & Education and Information Technologies & 1 \\
\hline & Information Systems Frontiers & 1 \\
\hline & International Journal of Intelligent Systems and Applications & 1 \\
\hline
\end{tabular}




\begin{tabular}{|l|l|l|}
\hline \multirow{2}{*}{} & Internet Research & 1 \\
\cline { 2 - 3 } Journal of Computing in Higher Education & 2 \\
\cline { 2 - 3 } & Procedia Computer Science & 1 \\
\cline { 2 - 3 } & Romanian Journal of Human - Computer Interaction & 1 \\
\cline { 2 - 3 } & Soft Computing & 1 \\
\hline
\end{tabular}

Answering the RQ1 defined previously, we found 32 papers concerning the use of the TensorFlow framework as a solution for educational problems published since 2016 to present in varying publication venues. $50 \%$ of them have been published in conferences.

Table 5 shows a detailed analysis of the filtered papers informing the main goal and the approaches used. In two papers there was no specific approach because one presents a common architecture and another shows a systematic review; for those papers the approach was listed as "General".

Table 5. Goal of the Papers Selected

\begin{tabular}{|c|c|c|}
\hline Reference & Goal & Approaches \\
\hline (Olivé et al., 2018) & To identify students at risk of abandoning a course & $\begin{array}{l}\text { Analytics framework for } \\
\text { Moodle }\end{array}$ \\
\hline $\begin{array}{l}\text { (Teruel \& Alonso } \\
\text { Alemany, 2018) }\end{array}$ & $\begin{array}{l}\text { To elicit insights on the relations between students } \\
\text { and contents }\end{array}$ & Neural network - unsupervised \\
\hline $\begin{array}{l}\text { (Castro-Wunsch et al., } \\
\text { 2017) }\end{array}$ & $\begin{array}{l}\text { To identify students who need assistance as early in } \\
\text { the course as possible }\end{array}$ & Neural network \\
\hline (Zhang et al., 2019) & $\begin{array}{l}\text { To propose a heterogeneous graph neural network } \\
\text { model, HetGNN, to representation learning }\end{array}$ & Graph neural network \\
\hline (Lee \& Yeung, 2019) & $\begin{array}{l}\text { To trace the knowledge of students as they solve a } \\
\text { sequence of problems represented by their related } \\
\text { skills }\end{array}$ & Neural network \\
\hline (Guo \& Zeng, 2020) & $\begin{array}{l}\text { To propose a federated learning-based education } \\
\text { data analysis framework FEEDAN, via which } \\
\text { pedagogical data federations can be formed by a } \\
\text { number of institutions }\end{array}$ & $\begin{array}{l}\text { Many servers collaboratively } \\
\text { train a common model with } \\
\text { their own local training data } \\
\text { under the orchestration of an } \\
\text { aggregation server }\end{array}$ \\
\hline (Malekian et al., 2020) & $\begin{array}{l}\text { To assist educators or online learning environments } \\
\text { to postpone assessment tasks until students were } \\
\text { deemed "ready" }\end{array}$ & Sequential pattern mining \\
\hline $\begin{array}{l}\text { (Hernández-Blanco et } \\
\text { al., 2019) }\end{array}$ & $\begin{array}{l}\text { To identify the educational data mining tasks that } \\
\text { have benefited from deep learning and those that } \\
\text { are pending to be explored }\end{array}$ & Neural network \\
\hline $\begin{array}{l}\text { (Vijayalakshmi \& } \\
\text { Venkatachalapathy, } \\
\text { 2019) }\end{array}$ & $\begin{array}{l}\text { To compare the prediction of the student } \\
\text { performance using different algorithms }\end{array}$ & $\begin{array}{l}\text { Decision tree, naive Bayes, } \\
\text { random forest, support vector } \\
\text { machine, K-Nearest neighbor, } \\
\text { and deep neural network }\end{array}$ \\
\hline (Wang et al., 2019) & $\begin{array}{l}\text { To develop a predictive model for effective } \\
\text { learning feature extracting, learning performance } \\
\text { predicting and result reasoning }\end{array}$ & $\begin{array}{l}\text { Convolutional GRU and } \\
\text { neural network }\end{array}$ \\
\hline $\begin{array}{l}\text { (Gutu-Robu et al., } \\
\text { 2018) }\end{array}$ & $\begin{array}{l}\text { To introduce an updated version or our open-source } \\
\text { NLP framework, ReaderBench, designed to support } \\
\text { both students and tutors in multiple learning } \\
\text { scenarios }\end{array}$ & Natural language processing \\
\hline (Boncea et al., 2019) & To improve scholar performance by a continuous & Assessment reusable learning \\
\hline
\end{tabular}




\begin{tabular}{|c|c|c|}
\hline & $\begin{array}{l}\text { and intelligent monitoring and assessing process of } \\
\text { daily knowledge gains }\end{array}$ & object and neural network \\
\hline (Pablo, 2020) & $\begin{array}{l}\text { To detect students who are at risk of failing the } \\
\text { course or need special support, providing teachers } \\
\text { with a useful mechanism for predicting and } \\
\text { improving student outcomes }\end{array}$ & $\begin{array}{l}\text { Learning experience } \\
\text { (academic performance and } \\
\text { online activity) }\end{array}$ \\
\hline (Cheng \& Zhang, 2020) & $\begin{array}{l}\text { To identify the most attractive collaboration } \\
\text { features that enterprises can offer to increase } \\
\text { university students' participation intentions }\end{array}$ & Online behaviours \\
\hline (Aveleyra et al., 2018) & $\begin{array}{l}\text { To predict which students may have problems in } \\
\text { the second exam and help them with the aim of } \\
\text { increasing the number of students who pass the } \\
\text { exam. }\end{array}$ & Deep neural network \\
\hline $\begin{array}{l}\text { (Tsiakmaki \& } \\
\text { Kostopoulos, 2020) }\end{array}$ & $\begin{array}{l}\text { To propose a transfer learning method for the task } \\
\text { of predicting student performance in undergraduate } \\
\text { courses }\end{array}$ & $\begin{array}{l}\text { Transfer learning and neural } \\
\text { network }\end{array}$ \\
\hline (Gudivada, et al., 2016) & $\begin{array}{l}\text { To propose a reference architecture for cognitive } \\
\text { analytics and indicate ways to implement the } \\
\text { architecture }\end{array}$ & General \\
\hline (Czibula et al., 2019) & $\begin{array}{l}\text { To predict the final grade of students of a certain } \\
\text { academic class }\end{array}$ & Relational association rules \\
\hline (Stoica, et al., 2019) & $\begin{array}{l}\text { To provide a more sophisticated method to improve } \\
\text { the search of educational videos and thus show } \\
\text { those that best fit the learning objectives of students }\end{array}$ & Support vector machine \\
\hline (Crivei et al., 2019) & $\begin{array}{l}\text { To predict the most appropriate output class (pass } \\
\text { or fail) for a student }\end{array}$ & Relational association rules \\
\hline $\begin{array}{l}\text { (Monllaó Olivé, et al., } \\
\text { 2020) }\end{array}$ & $\begin{array}{l}\text { To identify students at risk of dropping out of a } \\
\text { Massive Open Online Courses }\end{array}$ & Neural network - supervised \\
\hline (Chunqiao et al., 2018) & $\begin{array}{l}\text { To predict student study failure risk in early time } \\
\text { and improve the efficiency and effectiveness of } \\
\text { early warning education }\end{array}$ & Neural network \\
\hline (Holmes, 2020) & $\begin{array}{l}\text { To introduce the Artificial Intelligence in Education } \\
\text { approach, its set of technologies and a field of } \\
\text { inquiry }\end{array}$ & General \\
\hline (Moore et al., 2019) & $\begin{array}{l}\text { To generate personalized homework assignments } \\
\text { for students using behavioural cloning of teacher } \\
\text { activity }\end{array}$ & Neural network \\
\hline $\begin{array}{l}\text { (Preuveneers et al., } \\
\text { 2020) }\end{array}$ & $\begin{array}{l}\text { To observe the behavior of the audience and } \\
\text { keeping the participants engaged }\end{array}$ & $\begin{array}{l}\text { Edge-based multi-modal } \\
\text { engagement solution }\end{array}$ \\
\hline $\begin{array}{l}\text { (Pensel \& Kramer, } \\
\text { 2020) }\end{array}$ & $\begin{array}{l}\text { to forecast of the study success in selected STEM } \\
\text { disciplines (computer science, mathematics, } \\
\text { physics, and meteorology), solely based on the } \\
\text { academic record of a student so far, without access } \\
\text { to demographic or socioeconomic data }\end{array}$ & $\begin{array}{l}\text { random forest, support vector } \\
\text { machine, multilayer } \\
\text { perceptron, long short-term } \\
\text { memory networks }\end{array}$ \\
\hline $\begin{array}{l}\text { (Yang \& Cheung, } \\
\text { 2018) }\end{array}$ & $\begin{array}{l}\text { To propose an automatic and effective way to pre- } \\
\text { process the heterogeneous features into the deep } \\
\text { knowledge tracing model }\end{array}$ & $\begin{array}{l}\text { Neural network and tree based } \\
\text { classifiers }\end{array}$ \\
\hline $\begin{array}{l}\text { (Körösi \& Farkas, } \\
\text { 2020) }\end{array}$ & $\begin{array}{l}\text { To predict student performance at the end of the } \\
\text { Massive Open Online Course using directly raw log } \\
\text { data }\end{array}$ & Recurrent neural network \\
\hline (Injadat et al., 2020) & $\begin{array}{l}\text { To predict the students' performance at two stages } \\
\text { of course delivery }(20 \% \text { and } 50 \%)\end{array}$ & $\begin{array}{l}\text { K-nearest neighbor, random } \\
\text { forest, support vector machine, } \\
\text { multinomial logistic }\end{array}$ \\
\hline
\end{tabular}




\begin{tabular}{|l|l|l|}
\hline & & $\begin{array}{l}\text { regression, naive Bayes, and } \\
\text { neural network }\end{array}$ \\
\hline (Sha \& Hong, 2017) & $\begin{array}{l}\text { To model complex representations of student } \\
\text { knowledge and predict future performances of } \\
\text { students. }\end{array}$ & Recurrent neural network \\
\hline (Doleck et al., 2020) & $\begin{array}{l}\text { To compare the performance of some machine } \\
\text { learning algorithms (predictive accuracy) }\end{array}$ & $\begin{array}{l}\text { Support vector machines, k- } \\
\text { nearest neighbors, naive Bayes } \\
\text { classifier, and logistic } \\
\text { regression }\end{array}$ \\
\hline (Qiu et al., 2019) & $\begin{array}{l}\text { To predict the student dropout problem in Massive } \\
\text { Open Online Courses using the clickstream data }\end{array}$ & \begin{tabular}{l} 
Convolutional neural network \\
\hline
\end{tabular} \\
\hline
\end{tabular}

In order to answer RQ2, we identified several types of educational problems, such as student modeling, representation learning, knowledge tracing, pedagogical data analytics, decision support system, and evaluation. The student modeling is the most investigated focus area (found in 19 papers).

Regarding the approaches used, answering RQ3, 21 of the 32 selected papers have proposed a neural network (recurrent/convolutional/supervised/unsupervised) as the alternative to solve most of the educational problems. Analyzing deeply these papers, according to the results obtained, we can know that: 1- Keras, a neural networks library, has been used as wrapper to TensorFlow (Vijayalakshmi \& Venkatachalapathy, 2019); 2 - ReLU has been used as activation function of neural network to avoid overfitting (Wang et al., 2019); 3 - To train a model for longer (high number of epoch) does not guarantee a better result (Aveleyra et al., 2018); 4 - The neural networks with raw datasets have more sensitivity to "catch" patterns than XGBoost or XGBoost-regression models (Körösi \& Farkas, 2020); and 5 - Logistic regression has performed better when the amount of data is small (approximately 12,000 instances), and convolutional neural networks have performed better when the amount of data is large (approximately 120,500 instances) (Qiu et al., 2019). About the number of layers, most of the reviewed papers, informs that add more hidden layers improves the performance of the neural network.

Other approaches supported in the academic literature included: support vector machines (5 papers), Naïve Bayes ( 3 papers), and K-nearest neighbor ( 3 papers). Also some papers mentioned more than one approach for application, comparing performance, accuracy, and precision such as Vijayalakshmi \& Venkatachalapathy (2019), Pensel \& Kramer (2020), Injadat et al. (2020), and Doleck et al. (2020).

\section{Conclusion}

As students and researchers of the teaching degree Computer Science course have a significant educational background, it is easier to explore the Educational Data Mining area, seeking alternative ways to teach, resources to measure students' performance, and so on. This paper presented a systematic mapping regarding academic studies that use the TensorFlow framework to solve a myriad of educational problems, that can also be viewed as opportunities, in the last years. Each phase of the methodology applied was explained and shown the found results. In the last phase, Data Extraction and Mapping Process, we extracted the main information from 32 selected papers in order to know how the TensorFlow framework has been leveraged, identified the specific approach, and identified what the problem being solved in the academic sphere. Overall, we detected a robust number of papers that reference the student modeling problem using a (recurrent, convolutional, supervised, or 
unsupervised) neural network approach. None of the papers examined here shown their implementation.

\section{Acknowledgement}

We thank the Joe Oquist for his special English review.

\section{References}

Abadi, M., Barham, P., Chen, J., Chen, Z., Davis, A., Dean, J.; Devin, M., Ghemawat, S., Irving, G., Isard, M., Kudlur, M., Levenberg, J., Monga, R., Moore, S., Murray, D., Steiner, B., Tucker, P., Vasudevan, V., Warden, P., Wicke, M., Yu, Y. \& Zheng, X. (2016). TensorFlow: A system for largescale machine learning. 12th USENIX Symposium on Operating Systems Design and Implementation (OSDI 16), USENIX Association, 265-283.

Aveleyra, E., Proyetti, M., \& Racero, D. (2018). Performance Forecasting of University Students Using Machine Learning. European Conference on E-Learning, 40-44. https://search.proquest.com/compscijour/docview/2154984648/abstract/E1668EEDE538409APQ/4

Bakhshinategh, B., Zaïane, O., Elatia, S., \& Ipperciel, D. (2017). Educational data mining applications and tasks: A survey of the last 10 years. Education and Information Technologies. https://link.springer.com/article/10.1007/s10639-017-9616-z

Boncea, R., Petre, I., Vevera, V., \& Gheorghiţă, A. (2019). Machine Learning Based Methods Used for Improving Scholar Performance. The International Scientific Conference ELearning and Software for Education, Bucharest, 2, 471-478. http://dx.doi.org/10.12753/2066-026X-19-135

Castro-Wunsch, K., Ahadi, A., \& Petersen, A. (2017). Evaluating Neural Networks as a Method for Identifying Students in Need of Assistance. Proceedings of the 2017 ACM SIGCSE Technical Symposium on Computer Science Education, 111-116. https://doi.org/10.1145/3017680.3017792

Cheng, X., Zhang, Z., Yang, Y., \& Yan, Z. (2020). Open collaboration between universities and enterprises: A case study on GitHub. Internet Research, Bradford, 30(4), 1251-1279. http://dx.doi.org/10.1108/INTR-01-2019-0013

Cheung, L. P., \& Yang, H. (2017). Heterogeneous Features Integration in Deep Knowledge Tracing. In D. Liu, S. Xie, Y. Li, D. Zhao, \& E.-S. M. El-Alfy (Eds.), Neural Information Processing, Springer International Publishing, 653-662. https://doi.org/10.1007/978-3-319-70096-0_67

Chunqiao, M., Xiaoning, P., \& Qingyou, D. (2018). An Artificial Neural Network Approach to Student Study Failure Risk Early Warning Prediction Based on TensorFlow. In G. Sun \& S. Liu (Eds.), Advanced Hybrid Information Processing, Springer International Publishing, 326-333. https://doi.org/10.1007/978-3-319-73317-3_38

Crivei, L. M., Czibula, G., \& Mihai, A. (2019). A Study on Applying Relational Association Rule Mining Based Classification for Predicting the Academic Performance of Students. In C. Douligeris, D. Karagiannis, \& D. Apostolou (Eds.), Knowledge Science, Engineering and Management, Springer International Publishing, 287-300. https://doi.org/10.1007/978-3-030-29551-6_25

Czibula, G., Mihai, A., \& Crivei, L. M. (2019). S PRAR: A novel relational association rule mining classification model applied for academic performance prediction. Procedia Computer Science, 159, 20-29. https://doi.org/10.1016/j.procs.2019.09.156 
Doleck, T., Lemay, D. J., Basnet, R. B., \& Bazelais, P. (2020). Predictive analytics in education: A comparison of deep learning frameworks. Education and Information Technologies, 25(3), 19511963. https://doi.org/10.1007/s10639-019-10068-4

Gudivada, V. N., Irfan, M. T., Fathi, E., \& Rao, D. L. (2016). Cognitive Analytics: Going Beyond Big Data Analytics and Machine Learning. In Venkat N. Gudivada, V. V. Raghavan, V. Govindaraju, \& C. R. Rao (Eds.), Handbook of Statistics (Vol. 35, pp. 169-205). Elsevier. https://doi.org/10.1016/bs.host.2016.07.010

Guo, S., \& Zeng, D. (2020). Pedagogical Data Federation toward Education 4.0. Proceedings of the 2020 The 6th International Conference on Frontiers of Educational Technologies, 51-55. https://doi.org/10.1145/3404709.3404751

Gutu-Robu, G., Sirbu, M. D., Paraschiv, I., Dascalu, M., Dessus, P., \& Trausan-Matu, S. (2018). Liftoff - ReaderBench introduces new online functionalities. Romanian Journal of Human Computer Interaction, Bucuresti, 11(1), 76-91.

Hernández-Blanco, A., Herrera-Flores, B., Tomás, D., Navarro-Colorado, B. (2019). A Systematic Review of Deep Learning Approaches to Educational Data Mining. Complexity; Hoboken, http://dx.doi.org/10.1155/2019/1306039

Holmes, W. (2020). Artificial Intelligence in Education. In A. Tatnall (Ed.), Encyclopedia of Education and Information Technologies, Springer International Publishing, 88-103. https://doi.org/10.1007/978-3-030-10576-1_107

Injadat, M., Moubayed, A., Nassif, A. B., \& Shami, A. (2020). Multi-split optimized bagging ensemble model selection for multi-class educational data mining. Applied Intelligence. https://doi.org/10.1007/s10489-020-01776-3

Körösi, G., \& Farkas, R. (2020). MOOC Performance Prediction by Deep Learning from Raw Clickstream Data. In M. Singh, P. K. Gupta, V. Tyagi, J. Flusser, T. Ören, \& G. Valentino (Eds.), Advances in Computing and Data Sciences, Springer, 474-485. https://doi.org/10.1007/978-981-156634-9_43

Lee, J., \& Yeung, D.-Y. (2019). Knowledge Query Network for Knowledge Tracing: How Knowledge Interacts with Skills. Proceedings of the 9th International Conference on Learning Analytics \& Knowledge, 491-500. https://doi.org/10.1145/3303772.3303786

Malekian, D., Bailey, J., \& Kennedy, G. (2020). Prediction of students' assessment readiness in online learning environments: The sequence matters. Proceedings of the Tenth International Conference on Learning Analytics \& Knowledge, 382-391. https://doi.org/10.1145/3375462.3375468

Monllaó Olivé, D., Huynh, D. Q., Reynolds, M., Dougiamas, M., \& Wiese, D. (2020). A supervised learning framework: Using assessment to identify students at risk of dropping out of a MOOC. Journal of Computing in Higher Education, 32(1), 9-26. https://doi.org/10.1007/s12528-019-09230-1

Moore, R., Caines, A., Rice, A., \& Buttery, P. (2019). Behavioural Cloning of Teachers for Automatic Homework Selection. In S. Isotani, E. Millán, A. Ogan, P. Hastings, B. McLaren, \& R. Luckin (Eds.), Artificial Intelligence in Education (pp. 333-344). Springer International Publishing. https://doi.org/10.1007/978-3-030-23204-7_28

Olivé, D. M., Huynh, D. Q., Reynolds, M., Dougiamas, M., \& Wiese, D. (2018). A supervised learning framework for learning management systems. Proceedings of the First International Conference on Data Science, E-Learning and Information Systems, 1-8. https://doi.org/10.1145/3279996.3280014 
Pablo, S., Link to external site, this link will open in a new window, Navon, J., \& Pérez-Sanagustín, M. (2020). Models to provide guidance in flipped classes using online activity. Journal of Computing in Higher Education; Dordrecht, 32(2), 282-306. http://dx.doi.org/10.1007/s12528-019-09233-y

Pensel, L., \& Kramer, S. (2020). Forecast of Study Success in the STEM Disciplines Based Solely on Academic Records. In P. Cellier \& K. Driessens (Eds.), Machine Learning and Knowledge Discovery in Databases (pp. 647-657). Springer International Publishing. https://doi.org/10.1007/978-3-03043823-4_51

Petersen, K., Feldt, R., Mujtaba, S., \& Mattsson, M. (2008). Systematic Mapping Studies in Software Engineering. In: EASE'08 Proceedings of the 12th International Conference on Evaluation and Assessment in Software Engineering, 68-77

Preuveneers, D., Garofalo, G., \& Joosen, W. (2020). Cloud and edge based data analytics for privacypreserving multi-modal engagement monitoring in the classroom. Information Systems Frontiers. https://doi.org/10.1007/s10796-020-09993-4

Qiu, L., Liu, Y., Hu, Q., \& Liu, Y. (2019). Student dropout prediction in massive open online courses by convolutional neural networks. Soft Computing, 23(20), 10287-10301. https://doi.org/10.1007/s00500-018-3581-3

Sha, L., \& Hong, P. (2017). Neural Knowledge Tracing. Brain Function Assessment in Learning, Lecture Notes in Computer Science, 108-117. https://doi.org/10.1007/978-3-319-67615-9_10

Stoica, A. S., Heras, S., Palanca, J., Julian, V., \& Mihaescu, M. C. (2019). A Semi-supervised Method to Classify Educational Videos. International Conference Hybrid Artificial Intelligent Systems, 218228. https://doi.org/10.1007/978-3-030-29859-3_19

Teruel, M., \& Alonso Alemany, L. (2018). Co-embeddings for Student Modeling in Virtual Learning Environments. Proceedings of the 26th Conference on User Modeling, Adaptation and Personalization, 73-80. https://doi.org/10.1145/3209219.3209227

Tsiakmaki, M., Kostopoulos, G., Kotsiantis, S., \& Ragos, O. (2020). Transfer Learning from Deep Neural Networks for Predicting Student Performance. Applied Sciences, Basel, 10(6), 2145. http://dx.doi.org/10.3390/app10062145

Vijayalakshmi, V., \& Venkatachalapathy, K. (2019). Comparison of Predicting Student's Performance using Machine Learning Algorithms. International Journal of Intelligent Systems and Applications, Hong Kong, 11(12), 34. http://dx.doi.org/10.5815/ijisa.2019.12.04

Wang, X., Wu, P., Liu, G., Huang, Q., Hu, X., \& Xu, H. (2019). Learning performance prediction via convolutional GRU and explainable neural networks in e-learning environments. Computing, 101(6), 587-604. https://doi.org/10.1007/s00607-018-00699-9

Wang, X., Wu, P., Liu, G., Huang, Q., Hu, X., \& Xu, H. (2019). Learning performance prediction via convolutional GRU and explainable neural networks in e-learning environments. Computing, Archives for Informatics and Numerical Computation, 101(6), 587-604. http://dx.doi.org/10.1007/s00607-018-00699-9

Yang, H., \& Cheung, L. P. (2018). Implicit Heterogeneous Features Embedding in Deep Knowledge Tracing. Cognitive Computation, 10(1), 3-14. https://doi.org/10.1007/s12559-017-9522-0

Zhang, C., Song, D., Huang, C., Swami, A., \& Chawla, N. V. (2019). Heterogeneous Graph Neural Network. Proceedings of the 25th ACM SIGKDD International Conference on Knowledge Discovery \& Data Mining, 793-803. https://doi.org/10.1145/3292500.3330961 